\section{Illustrated Technical Dictionary}

Containing Standard Technical Definitions of Current Terms in the Applied Sciences, Graphic and Industrial Arts, and Mechanical Trades; including Air Navigation, Meteorology, Shipbuilding, Syntheties and Plastics; with Illustrations, Technical Data and Interconversion Tables. Edited by Maxim Newmark. Pp. xii 352. (New York: Philosophical Library, Inc., 1944.) 5 dollars.

$\mathrm{T}$ ECHNICAL dictionaries are multiplying rapidly to meet the growing needs of a progressive civilization, and the Philosophical Library, New York, is placing itself in the vanguard of publishers who respond to this demand. Its new illustrated technical dictionary will be welcomed by scientific and technical workers of almost every kind ; the book should find a home in most general libraries. The explanatory sub-title gives a good idea of its scope, with the emphasis on the mechanical arts, and the illustrations, which have been supplied mainly by engineering firms of standing, will be found very useful. The multiplicity of subjects and the necessarily limited space will doubtless invite some adverse criticism concerning lack of balance; but what may be important to the engineer or 'wireless' expert may be of little interest to the chemist, and vice versa. A primary consideration is that first things should be placed first, and in this respect there is little to cavil at in the present work; only a few slips and omissions have been noticed. The definition given of permeability refers only to gaseous diffusion : electric and magnetic permeability are not mentioned. The Baumé hydrometer is defined as a scale for measuring the density of a liquid. The chief use of ammonium sulphate, namely, as a fertilizer, is not given, nor is the use of urea in the manufacture of plastics. The uses of so many chemical products for so many purposes suggest that there is scope for a separate publication on this subject. It would be compendious and need, constant revision, but it would be a boon to many manufacturers and industrialists; and it would form a useful companion volume to the present work of reference.

E. H. T.

\section{Joint Progress Report on Reservoir Efficiency and Well Spacing}

By the Committees on Reservoir Development and Operation of the Standard Oil Company (New Jersey) Affiliated Companies and of the Humble Oil and Refining Company. Pp. xix +77 . (New York : Standard Oil Development Co.; London: AngloAmerican Oil Co., Ltd., 1944.)

THIS report embodies the findings of two com. mittees appointed respectively by the Standard Oil Co. (New Jersey) Affiliated Companies and the Humble Oil and Refining Co. to collate and interpret data on the effects of field operating practices and well spacing on the efficiency of oil recovery from natural underground resources. Each of the committees carried out pool studies of actual fields to obtain information on reservoir behaviour and oil recovery under various well-spacing and operating practices, in addition to a review of all available theory and research data.

It is concluded that the degree to which basic oil recovery mechanisms (dissolved gas drive, gas cap drive and water drive) will operate in practice, and possible oil yields obtainable, together with optimum economic well-spacing for a particular field, are dependent on physical conditions in the reservoir and on the limiting effect of economics or other imposed restrictions. Probably the most important physical factors governing potential recovery are sand permeability and oil viscosity, high permeability and low viscosity being nearly always conducive to high yield. Economic conditions determine the point at which operations must be abandoned for reasons of cost, and equally they govern decisions on optimum well spacing. As a result of their studies the committees advocate that the securing and recording of requisite data should be a major objective in field development and operation. Records required from each individual reservoir include data on structure and sand-thicknesses, complete analyses of subsurface samples of reservoir fluids, sub-surface pressure survey readings, productivity factors, and gas, oil and water production figures.

\section{Introductory Magnetism and Electricity}

By T. M. Yarwood. Pp. vii+159. (London: Macmillan and Co., Ltd., 1944.) 2s. $6 d$.

$\mathrm{N}$ writing this small volume, the author has provided 1 mainly for those preparing to enter one of the technical branches of the Services. It should be very suitable for cadets in the Air Training Corps. The subject-matter admirably covers all that is necessary in pre-service training. In this, it fulfils one of the two objects stated in the preface. It might not be, however, so successful in achieving the other, which is to stimulate further reading in the subject. It is too condensed and 'heavy-going' to be inspiring to the beginner.

It is surprising that alternating current is not dealt with at greater length. One would have expected to find a whole chapter on this topic.

The book is well arranged and well printed, with many diagrams. Its chief defect is the limp cloth binding. It is to be regretted that war-time economy does not permit a more attractive and permanent binding.

At its published price the book should have a good circulation and is, without doubt, an excellent, though brief, text, superior to many others at much higher prices.

\section{Manual of Laboratory Glass-Blowing}

By Prof. R. H. Wright. Pp. ix $+90+11$ plates. (Brooklyn, N.Y.: Chemical Publishing Co., Inc., 1943.) 2.50 dollars.

$\mathrm{T}$ this manual the author describes a number of processes which are constantly needed for the construction of laboratory glass apparatus. After discussing the composition and the characteristics of various glasses, a description is given of tools and their usage in the construction of both simple and advanced types of glass apparatus.

In dealing with such a subject no written directions can take the place of personal instruction or individual skill, so that the value of such a manual is enhanced if the diagrams show salient features of the process in progress. The author has attempted to do this by means of original photographs.

The book contains much useful information, and will be of service to the laboratory worker. Its usefulness would have been further increased, at least for the beginner, if more details had been given as to the most suitable gas or oxy-gas flame to use for various types of work.
A. J. A. 